\title{
Gas exchange of three dipterocarp species in a reciprocal planting.
}

\begin{abstract}
Gas exchange is important for determining the species plasticity. However, study on gas exchange in dipterocarp is almost non-existence and this study may provide useful information for future references. The study was conducted at the Compartment 14, Ayer Hitam Forest Reserve, Puchong and Selangor, Malaysia. The main objective of this study was to determine the leaf gas exchange of three dipterocarps, Shorea platyclados V. SI. ex Foxw. (meranti bukit), Shorea assamica Dyer forma globifera (Ridl) Sym. (meranti pipit) and Anisoptera marginata Korth. (mersawa paya) planted in different sizes of gap. The results showed that the gas exchange parameters were not significantly different between species except stomatal conductance (Gs) and transpiration rate (EL). Insignificant differences of all the gas exchange parameters were also observed between planting designs. Meanwhile, the correlation analysis showed that insignificant effect of design on species for net photosynthesis (Anet) is due to the effect of internal CO2 concentration (Ci). However, the significant difference observed for transpiration rate (EL) between species might be due to the significant roles of stomata conductance (Gs). Overall, the higher tropical species plasticity by introducing reciprocal planting in rehabilitation programme has produced mixed results.
\end{abstract}

Keyword: Genecology; Net photosynthesis; Plasticity; Shorea species; Stomata conductance. 